\title{
EVALUATION OF THE EFFECTS OF MAXILLARY EXPANSION AND PROTRACTION ON FACIAL SOFT TISSUE PROFILE IN UNILATERAL CLEFT LIP AND PALATE PATIENTS USING CONE BEAM COMPUTED TOMOGRAPHY
}

\author{
Ahmed Sh. Hashem*, Omar Aboulmakarem ${ }^{* *}$ and Wael M. Refai***
}

\begin{abstract}
Aim: The aim of this study was to evaluate 3 dimensionally the influence of maxillary expansion and protraction on the facial soft tissue profile in unilateral cleft lip and palate patients with skeletal Class III malocclusion.

Materials and Methods: This retrospective study included 2 groups. The first treatment group included randomly selected CBCT scans of 15 unilateral cleft lip and palate patients ( 8 males and 7 females, mean age $8.3 \pm 1$ years) with skeletal Class III treated with Hyrax expander for rapid expansion and face mask appliance for maxillary protraction. The CBCT scans for each patient were available before starting the treatment (T1) and after a positive overjet was achieved (T2). The soft tissue profile changes in the treatment group were compared with a closely matched second control group with skeletal Class I relation (7 males and 8 females, mean age of $8.5 \pm 1.1$ years).
\end{abstract}

Results: Upper lip protrusion, $\mathrm{H}$ angle, prominence of the nose and soft tissue facial height showed statistically significant increase in the first than the second group $(\mathrm{P}<0.001)$. Lower lip protrusion, angle of facial convexity, nasolabial angle and soft tissue chin prominence showed statistically significant decrease in the first than the second group $(\mathrm{P}<0.001)$.

Conclusions: Unilateral cleft lip and palate patients with skeletal Class III malocclusion showed significant improvement in the facial soft tissue profile when treated with hyrax expander and face mask.

KEY WORDS: Cleft lip and palate, Face mask appliance, Hyrax expander, Facial soft tissue profile, Cone beam computed tomography.

\footnotetext{
* Lecturer of orthodontics, Faculty of Dentistry, Minia University, Egypt

** Msc in orthodontics, Minia University, Egypt

*** Professor of orthodontics, Faculty of Dentistry, Minia University, Egypt
} 


\section{INTRODUCTION}

Non-syndromic clefts of the lip and palate are one of the most frequent craniofacial deformities with an incidence of about 1 in every 600 live births in the world ${ }^{1}$. Cleft patients usually display various orofacial problems as missing and unerupted teeth, defective alveolar bone support, collapsed upper arch and severe anterior and posterior cross bites ${ }^{2,3}$.

A number of treatment approaches had been presented for cleft patients to improve function and facial appearance, including several surgical closure techniques of the clefts. The resulting scar tissues and the asymmetry around the nose and the mouth from these surgical interventions diminished the facial attractiveness ${ }^{4-6}$. Also, the combination of midface retrusion, nasolabial angle alteration and lower facial height change are more destructive to the facial attractiveness ${ }^{7}$.

Different physical, social and psychological effects of dentofacial deformities, including clefts are long-lasting points of research studies. Subjects looking for correction of dentofacial deformities mostly require improvement of both functional and esthetic problems ${ }^{8}$. Dentofacial deformities could have negative psychological outcomes on those patients 9 .

Because of the intimate relation between the facial soft tissues and underlying bony structures, orthodontic treatment could result in favorable effects on facial soft tissues ${ }^{10-13}$. Both effective occlusion and facial esthetics are considered parallel objectives of orthodontic therapy ${ }^{7}$.

The anteroposterior maxillary deficiency in cleft lip and palate patients is a frequent consequence to the postsurgical scar tissues. Also, transverse maxillary constriction in these patients results in unilateral or bilateral posterior crossbite ${ }^{14,15}$. Accordingly, the objectives of early treatment of these patients generally include enhancing forward and transverse maxillary growth. A treatment protocol including combined face mask and hyrax expander could be efficiently used for these purposes ${ }^{16,17}$.

Some previous studies evaluated the various consequences of maxillary widening and protraction in cleft lip and palate patients using lateral cephalometric radiographs ${ }^{7,18}$. Errors in these two dimensional radiographs could originate from improper patient positioning, difficult identification of landmarks and inaccurate measurements ${ }^{19,20}$. CBCT could provide a chance to overcome most of the restrictions related to landmark recognition, positioning faults and superimpositions in lateral cephalometric radiographs through image manipulation ${ }^{21}$.

Therefore, the aim of this study was to use cone beam computed tomography to evaluate the influence of maxillary expansion and protraction on the facial soft tissue profile in unilateral cleft lip and palate patients with skeletal Class III malocclusion.

\section{MATERIALS AND METHODS}

The ethical permission for this study was approved by the ethical committee of the Faculty of Dentistry, Minia University (Decision number 3762017). Sample size was determined according to Pandis $^{22}$ depending on a pilot study that included 7 randomly selected unilateral complete cleft lip and palate patients. The effect size for the angle of facial convexity was $1.1 \pm 0.9$ degrees. With a significance level of 0.05 and a power of study $90 \%$, the study included 15 patients in each group.

This retrospective study included 2 groups. The first treatment group included randomly selected CBCT scans of 15 patients (8 males and 7 females, mean age $8.3 \pm 1$ years). The CBCT scan for each patient was available before starting the treatment (T1) and after a positive overjet was achieved (T2). The inclusion criteria included:

1- Non-syndromic surgically repaired unilateral complete cleft lip and palate.

2- Skeletal Class III due to retarded maxillary growth $\left(\mathrm{SNA} \leq 77^{\circ}\right.$ degrees, $\left.\mathrm{ANB} \leq-2^{\circ}\right)$. 


\section{3- Anterior crossbite.}

4- Unilateral or bilateral posterior crossbite.

5- No history of previous orthodontic treatment.

The second untreated control group included randomly selected CBCT scans of 15 non-cleft patients ( 7 males and 8 females, mean age $8.5 \pm 1.1$ years) with the following inclusion criteria:

1- Skeletal Class I relation with SNA angle $=81 \pm 2^{\circ}$

2- Absence of anterior or posterior cross bites.

3- No previous orthodontic treatment

4- Age and sex were closely matched with the treatment group.

Patients of the control group had previously attained CBCT scans for diagnosing impacted or missing teeth, assessment of the bone level, or future orthodontic treatment. Table 1 shows the distribution of age and sex between both groups.

\section{Expansion and Protraction protocol:}

Hyrax expander (Leone, Firenze, Italy) was fabricated for each patient and soldered to the first permanent molar bands from the palatal side with 0.45 " stainless steel wire arms extending anteriorly bilaterally and adapted to the palatal surface of the premolars or the primary molars. Occlusal surfaces of the teeth were then covered with $1 \mathrm{~mm}$ resin to increase the surface area of the appliance for better cement adhesion and to eliminate occlusal interferences in the incisor region. Facemask hooks were soldered anteriorly at the maxillary canine area facing upwards for good attachment of elastics. The appliance was then cemented (Figure 1) and activated by opening the midline expansion screw two times per day $(0.25 \mathrm{~mm}$ per turn) until palatal cusp tips of the maxillary posterior teeth occluded opposite the buccal cusp tips of the mandibular posterior ones.

The orthopedic protraction was then started, using 5/16" elastics (American Orthodontics, Sheboygan, Wis) attached from the hooks to the facemask (Hubit Co.,Ltd, Gyeonggi-do, South

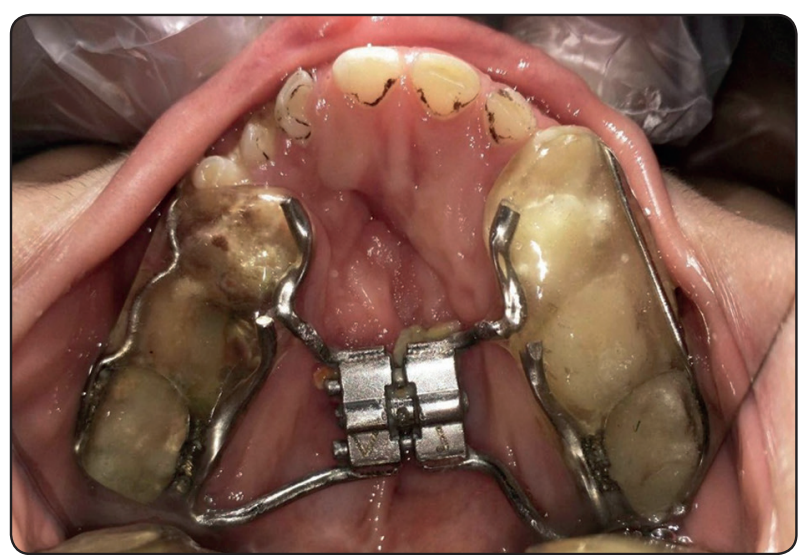

Fig. (1)

Korea). The facemask was adjusted on each patient's face (Figure 2) to render its pads comfortable and to make the angle between the elastics and the occlusal plane nearly 30 degrees to counteract the rotation of the maxilla in a counterclockwise direction ${ }^{23,24}$. Elastic force was measured with a force tension gauge (Dentaurum, Pforzheim, Germany).

All patients were instructed to wear the facemask at least 14 hours per day and to replace the elastics once a day or when they were lost. An evaluation chart was given to every patient to record the duration of elastics wear every day. Patients were followed up monthly to evaluate treatment progress

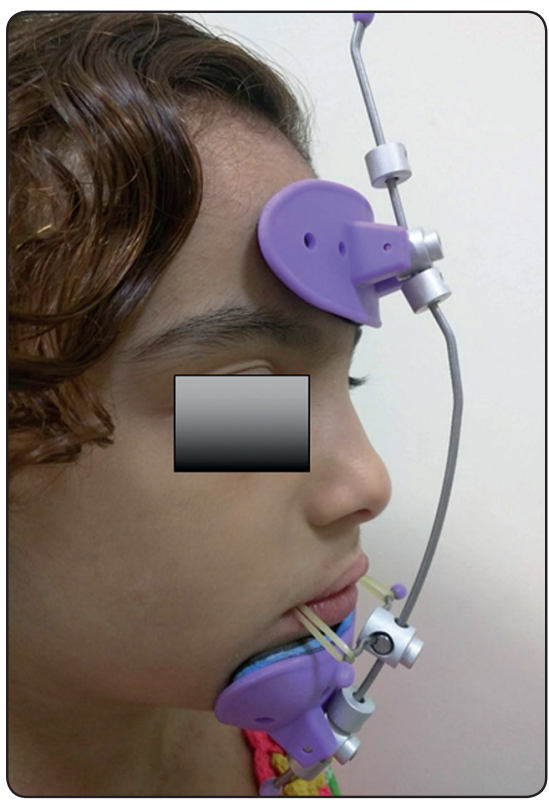

Fig. (2) 
and cooperation. The treatment was completed until $1 \mathrm{~mm}$ positive overjet was attained in all patients.

After all CBCT scans (Scanora 3Dx Soredex, Finland) were performed with the same standardized technique at $10 \mathrm{~mA}$ and $90 \mathrm{kV}$, data were exported and transferred to DICOM format (Digital Imaging and Communications in Medicine) with the i-CAT software (Hatfield, Pennsylvania, USA). A completely reconstructed 3 dimensional image was created by using the Mimics image processing software (Materialise Group, Leuven, Belgium).

The 3D images were subsequently reoriented to the Frankfort horizontal reference plane that was connecting the orbitale points (the most inferior points on the right and left bony orbits) and the right porion (the highest point on the right external auditory meatus). The sagittal reference plane was perpendicular to the horizontal reference plane and connecting the most anterior point on the frontonasal suture (nasion) and the right porion. The frontal plane was extended from the nasion and normal to the horizontal and sagittal planes.

Detection of landmarks was done by utilizing the generated multiplanar projections. The chosen points were then confirmed on the 3 dimensional images and the software calculated different measurements (Figure 3). Tables 2 and 3 show the landmarks and measurements used in this study.

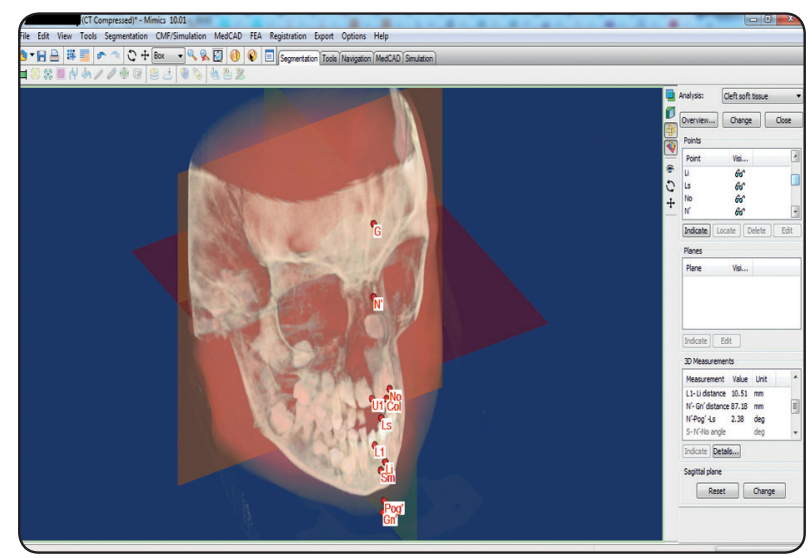

Fig. (3)

\section{Statistical method}

The collected data were coded, tabulated, and statistically analyzed using SPSS program (Statistical Package for Social Sciences) software version 25. Shapiro-Wilk test showed normal distribution of all variables ( $\mathrm{P}>0.05$ for all of them). Descriptive statistics were done for quantitative data by mean \pm standard deviation and for categorical data by number and percentage.

Analyses were done between both groups for parametric quantitative data using independent $\mathrm{T}$ test and for qualitative data using Chi square test (expected number per cell $>5$ ). The level of significance was taken at $\mathrm{P}$ value $<0.05$.

\section{Error of the method}

All reference points were relocated and all measurements were retaken by the same clinician 3 times with 2 weeks interval between each of them. Cronbach's Alpha was determined to evaluate the reliability of measurements.

\section{RESULTS}

The method reliability was excellent with Cronbach's Alpha more than 0.9 for all measurements in both groups. There was no statistically significant difference between both groups concerning age and sex (Table 1).

TABLE (1) Distribution of age and sex at T1 in both groups

\begin{tabular}{|c|c|c|c|c|}
\hline \multicolumn{2}{|l|}{} & $\begin{array}{c}\text { Treatment } \\
\text { group }\end{array}$ & Control group & P value \\
\cline { 1 - 4 } \multirow{凶}{凶}{} & Males & $8(53.3 \%)$ & $7(46.7 \%)$ & \multirow{2}{*}{0.605} \\
\cline { 2 - 4 } & Females & $7(46.7 \%)$ & $8(53.3 \%)$ & \\
\hline \multicolumn{2}{|c|}{ Age } & $8.3 \pm 1$ & $8.5 \pm 1.1$ & 0.126 \\
\hline
\end{tabular}

Parametric quantitative data expressed as mean \pm $S D$, while qualitative data expressed by frequency and percentage. Chi square test for qualitative data between both groups Independent samples $T$ test for parametric quantitative data between both groups. *: Significant level at $P$ value $<0.05$ 
Positive overjet was attained in all patients of the first group. The mean treatment duration was $1.6 \pm 0.4$ years. Three patients showed mobility in the expander during the treatment period. For these patients, the appliances were re-cemented, and the treatment was continued with the same protocol. The elastics produced a mean force of $426 \pm 29.5$ grams.

The upper lip protrusion was significantly increased in the first than the second group $(1.5 \pm 0.6$ degrees and $0.1 \pm 0.1$ degrees respectively, with $\mathrm{P}$-value $<0.001)$. The $\mathrm{H}$ angle was significantly increased in the first than the second group $(3.8 \pm 0.5$ degrees and $-0.4 \pm 0.2$ degrees respectively, with $\mathrm{P}$-value $<0.001)$. The prominence of the nose was significantly increased in the first than the second group $(1.9 \pm 0.9$ degrees and $0.3 \pm 0.2$ degrees respectively, with $\mathrm{P}$-value $<0.001)$. The soft tissue facial height was significantly increased in the first than the second group $(2.9 \pm 1.5 \mathrm{~mm}$ and $1.1 \pm 0.5$ $\mathrm{mm}$ respectively, with $\mathrm{P}$-value $=0.001$ )

The lower lip protrusion was significantly decreased in the first than the second group $(-1.1 \pm 0.4$ degrees and $0.4 \pm 0.2$ degrees respectively, with P-value $<0.001)$. The angle of facial convexity was significantly decreased in the first than the second group $-4.2 \pm 1.4$ degrees and $0.6 \pm 0.3$ degrees respectively, with $\mathrm{P}$-value $<0.001)$. The soft tissue chin prominence was significantly decreased in the first than the second group $-2 \pm 0.6$ degrees and $0.3 \pm 0.2$ degrees respectively, with $\mathrm{P}$-value $<0.001$ ). Results are summarized in Table 4.

TABLE (2) List of the three dimensional landmarks

\begin{tabular}{|l|l|}
\hline \multicolumn{1}{|c|}{ Point } & \\
\hline Sella (S) & The midpoint of the sella turcica \\
\hline Glabella (G) & The most prominent anterior point on the soft tissue of the forehead \\
\hline Soft tissue Nasion (N') & The deepest point on the concavity between soft tissue contour of the head and the nose \\
\hline Subnasale (Sn) & The point of meeting of the base of the columella with the upper lip \\
\hline Columella (Col) & The point of curvature of the base of the nose \\
\hline Labrale Superius (Ls) & The point denoting the junction of the vermillion border and the skin of the upper lip \\
\hline Subspinale (Ss) & The deepest point on the concavity between the subnasale (Sn) and the labrale superius (Ls) \\
\hline Labrale Inferius (Li) & The point denoting the junction of the vermillion border and the skin of the lower lip \\
\hline Soft tissue Pogonion (Pog') & The most prominent point on the soft tissue contour of the chin \\
\hline Submentale (Sm) & The deepest point on the concavity between the Labrale Inferius (Li) and the soft tissue pogonion (Pog') \\
\hline Soft tissue Gnathion (Gn') & The most anterior inferior point on the soft tissue contour of the chin \\
\hline Tip of nose (No) & The most anterior point at the tip of the nose \\
\hline
\end{tabular}

TABLE (3) List of CBCT linear and angular measurements

\begin{tabular}{|l|l|}
\hline \multicolumn{1}{|c|}{ Measurement } & \multicolumn{1}{c|}{ Definition } \\
\hline Upper lip protrusion & The angle S- N'-Ss \\
\hline Lower lip protrusion & The angle S- N'-Sm \\
\hline Angle of facial convexity & The angle G-Sn-Pog' \\
\hline H angle & The angle N'-Pog'-Ls \\
\hline Nasolabial angle & The angle Col -Sn- Ls \\
\hline Prominence of the nose & The angle S- N'-No \\
\hline Prominence of the soft tissue chin & The angle S-N'- Pog' \\
\hline Soft tissue facial height & The distance between N'and Gn' \\
\hline
\end{tabular}


TABLE (4) Three dimensional cephalometric measurements at T1 and their change between T2 and T1 in both groups

\begin{tabular}{|c|c|c|c|c|c|}
\hline & \multicolumn{2}{|c|}{ Group I } & \multicolumn{2}{|c|}{ Group II } & \multirow{2}{*}{$\begin{array}{l}\text { P value } \\
\text { (T2-T1) }\end{array}$} \\
\hline & $\mathrm{T} 1$ & $\mathrm{~T} 2-\mathrm{T} 1$ & $\mathrm{~T} 1$ & $\mathrm{~T} 2-\mathrm{T} 1$ & \\
\hline Upper lip protrusion & $86.2 \pm 1.6$ & $1.5 \pm 0.6$ & $92.4 \pm 1.7$ & $0.1 \pm 0.1$ & $<0.001 *$ \\
\hline Lower lip protrusion & $89.3 \pm 1.7$ & $-1.1 \pm 0.4$ & $90.5 \pm 1.7$ & $0.4 \pm 0.2$ & $<0.001 *$ \\
\hline Angle of facial convexity & $168.7 \pm 1.9$ & $-4.2 \pm 1.4$ & $159.5 \pm 1.9$ & $0.6 \pm 0.3$ & $<0.001 *$ \\
\hline $\mathrm{H}$ angle & $2.9 \pm 0.7$ & $3.8 \pm 0.5$ & $7.5 \pm 0.9$ & $-0.4 \pm 0.2$ & $<0.001^{*}$ \\
\hline Nasolabial angle & $119.2 \pm 1.8$ & $-3.2 \pm 0.9$ & $108.4 \pm 2.4$ & $-0.2 \pm 0.2$ & $<0.001^{*}$ \\
\hline Prominence of the nose & $104.2 \pm 2.4$ & $1.9 \pm 0.9$ & $113.3 \pm 2.5$ & $0.3 \pm 0.2$ & $<0.001 *$ \\
\hline Prominence of the soft tissue chin & $90.6 \pm 1.9$ & $-2 \pm 0.6$ & $91.7 \pm 2.4$ & $0.3 \pm 0.2$ & $<0.001^{*}$ \\
\hline Soft tissue facial height & $91.3 \pm 2.4$ & $2.9 \pm 1.5$ & $92.8 \pm 2.3$ & $1.1 \pm 0.5$ & $0.001 *$ \\
\hline
\end{tabular}

Parametric quantitative data expressed as mean $\pm S D$.

Independent samples $T$ test for parametric quantitative data between both groups.

*: Significant level at $P$ value $<0.05$.

\section{DISCUSSION}

The characteristic three-dimensional maxillary collapse in cleft lip and palate patients necessitates early growth modification during the deciduous and mixed dentition stages ${ }^{25}$. This early intervention could provide more advantageous conditions for midfacial growth, control the intermaxillary basal relation and prevent functional disturbances ${ }^{26}$.

Rapid maxillary expansion utilizing hyrax expander could result in significant increase in the maxillary transverse dimension in both the cleft and non-cleft sides. As the expansion is more significant in the posterior than the anterior area, the posterior cross bite is improved considerably ${ }^{15}$.

In this study, rapid maxillary expansion was continued until palatal cusp tips of the maxillary posterior teeth occluded opposite the buccal cusp tips of the mandibular posterior ones. Maxillary protraction was then started. The consequences of rapid palatal expansion included opening of the intermaxillary, internasal, maxillonasal, frontomaxillary and frontonasal sutures and The disarticulation of these circummaxillary sutures could assist the orthopedic outcome ${ }^{27-29}$.
The face mask is an efficient appliance for correcting skeletal Class III cases with a retruded maxilla particularly in hypo-divergent growth directions $\mathrm{s}^{30}$. Orthopedic forces were generated through elastics attached from the hooks to the face mask. As the center of resistance of the maxillary complex was located on the posterior wall of the maxillary sinus at the level of the pterygopalatine fossa ${ }^{31}$ and the point of force application was opposite to the primary canine where elastics were attached, a moment in a counterclockwise direction was created. This could produce more movement of the lower than the upper midface. To counteract this moment, the angle between the elastics and the occlusal plane was adjusted to be nearly 30 degrees $^{32}$.

With early orthopedic treatment, the ratio of the improvement in the hard to soft tissue was reported to be $50 \%$ to $79 \%$ in the maxilla and $71 \%$ to $81 \%$ in the mandible ${ }^{33}$. The effects of maxillary protraction on hard and soft tissues could reveal the intimate relation between both tissues ${ }^{27}$. The results of this study displayed the significant improvement of the soft tissue facial profile accompanying the combined hyrax/ face mask therapy. 
Upper lip protrusion was significantly increased in the treated group $\left(1.5^{\circ}\right)$ than the control group $\left(0.1^{\circ}\right)$. This was more than the $1.2^{\circ}$ increase reported by Tinlund et $\mathrm{al}^{31}$. This beneficial result could be related to the forward displacement of the maxilla as an outcome to the face mask therapy with lessening of the severe skeletal defects ${ }^{34}$. There was a significant reduction in the lower lip protrusion in the treated $\left(-1.1^{\circ}\right)$ compared with the control group $\left(0.4^{\circ}\right)$. This could be attributed to the change of the sagittal position of the mandible caused by the chin cup part of the face mask ${ }^{24}$.

The angle of facial convexity showed a significant reduction in in the treated $\left(-4.2^{\circ}\right)$ than the control group $\left(0.6^{\circ}\right)$. This was more compared with that reported by Pavoni et al $\left(-3.6^{\circ}\right)$ in skeletal Class III non cleft patients ${ }^{24}$. This result could be related to the combined significant maxillary advancement associated with reduction of the mandibular prognathism ${ }^{35}$.

The significant upper lip protrusion during maxillary advancement could interpret the significant reduction in nasolabial angle in the treated group with respect to the control group. The prominence of the nose was significantly increased in the treated group $\left(1.9^{\circ}\right)$ than the control group $\left(0.3^{\circ}\right)$. This was favorable to improve the inherent flattening of the nasal tip in cleft lip and palate patients ${ }^{36}$.

There was significant reduction of the prominence of the soft tissue chin in the treated group $\left(-2^{\circ}\right)$ than the control group $\left(0.3^{\circ}\right)$. Tinlund et al showed $-1.2^{\circ}$ change in the prominence ${ }^{31}$. This could be produced by 2 factors, force application on the chin from the chin cup portion of the face mask ${ }^{24}$ and the mandibular autorotation ${ }^{37}$. The significant increase in the soft tissue facial height was interpreted by the counterclockwise rotation of the maxilla with autorotation of the mandible ${ }^{24}$. This could improve the characteristic facial height reduction and jaw overclosure in cleft patients ${ }^{31}$.

\section{CONCLUSION}

Unilateral cleft lip and palate patients with skeletal Class III malocclusion showed significant improvement in the facial soft tissue profile when treated with hyrax expander and face mask.

\section{REFERENCES}

1- Mossey PA, Little J, Munger RG, et al. Cleft lip and palate. Lancet. 2009 21;374(9703):1773-1785.

2- Gandedkar NH, Chng CK, Basheer MA, et al. Comparative Evaluation of the Pharyngeal Airway Space in Unilateral and Bilateral Cleft Lip and Palate Individuals With Noncleft Individuals: A Cone Beam Computed Tomography Study. Cleft Palate Craniofac J. 2017;54(5):509-516.

3- Diwakar R, Sidhu MS, Jain S, et al. Three-dimensional evaluation of pharyngeal airway in complete unilateral cleft individuals and normally growing individuals using cone beam computed tomography. Cleft Palate Craniofac J. 2015;52(3):346-351

4- Pruzinsky T. Social and psychological effects of major craniofacial deformity. Cleft Palate Craniofac J. 1992;29(6):578-584.

5- Eichenberger M, Staudt CB, Pandis N, et al. Facial attractiveness of patients with unilateral cleft lip and palate and of controls assessed by laypersons and professionals. Eur J Orthod. 2014;36(3):284-292.

6- Patcas R, Timofte R, Volokitin A, et al. Facial attractiveness of cleft patients: a direct comparison between artificialintelligence-based scoring and conventional rater groups. Eur J Orthod. 2019 8;41(4):428-433.

7- Tindlund RS, Rygh P. Soft-tissue profile changes during widening and protraction of the maxilla in patients with cleft lip and palate compared with normal growth and development. Cleft Palate Craniofac J. 1993;30(5):454-468.

8- Cunningham SJ, Garratt AM, Hunt NP. Development of a condition-specific quality of life measure for patients with dentofacial deformity: I. Reliability of the instrument. Community Dent Oral Epidemiol 2000: 28:195-201.

9- Lee S, McGrath C, Samman N. Quality of life in patients with dentofacial deformity: a comparison of measurement approaches. Int J Oral Maxillofac Surg. 2007; 36(6):488492.

10- Altındiş S, Toy E, Başçiftçi FA. Effects of different rapid maxillary expansion appliances on facial soft tissues using three-dimensional imaging. Angle Orthod. 2016;86(4):590-597. 
11- Khan M, Fida M. Soft tissue profile response in extraction versus non-extraction orthodontic treatment. J Coll Physicians Surg Pak. 2010;20(7):454-462.

12- Bourzgui F, Alami S, Sebbar M, et al. Effect of orthodontic treatment on lip position. Int Orthod. 2013;11(3):303-313.

13- Aras I, Olmez S, Akay MC, et al. The effects of maxillary expansion on the soft tissue facial profile. J Istanb Univ Fac Dent. 2017 2;51(3):1-10.

14- Buschang PH, Porter C, Genecov E, et al. Face mask therapy of preadolescents with unilateral cleft lip and palate. Angle Orthod. 1994;64(2):145-150.

15- Figueiredo DS, Cardinal L, Bartolomeo FU, et al. Effects of rapid maxillary expansion in cleft patients resulting from the use of two different expanders. Dental Press J Orthod. 2016;21(6):82-90.

16- Nartallo-Turley P.E., Turley P.K. Cephalometric effects of combined palatal expansion and facemask therapy on Class III malocclusion. Angle Orthod. 1998;68(3):217-224.

17- Pavoni C, Masucci C, Cerroni S, et al. Short-term effects produced by rapid maxillary expansion and facemask therapy in Class III patients with different vertical skeletal relationships. Angle Orthod. 2015;85(6):927-933.

18- Jahanbin A, Kazemian M, Eslami N, et al. Maxillary Protraction With Intermaxillary Elastics to Miniplates Versus Bone-Anchored Face-Mask Therapy in Cleft Lip and Palate Patients. J Craniofac Surg. 2016;27(5):1247-1252.

19- Chen YJ, Chen SK, Chang HF, et al. Comparison of landmark identification in traditional versus computer-aided digital cephalometry. Angle Orthod. 2000;70(5):387-392.

20- Chen YJ, Chen SK, Yao JC, et al. The effects of differences in landmark identification on the cephalometric measurements in traditional versus digitized cephalometry. Angle Orthod. 2004;74(2):155-161.

21- Shaw K, McIntyre G, Mossey P, et al. Validation of conventional 2D lateral cephalometry using 3D cone beam CT. J Orthod. 2013;40(1):22-29.

22- Pandis N. Sample calculations for comparison of 2 means. Am J Orthod Dentofacial Orthop. 2012;141(4):519-521 .

23- Tanne K, Hiraga J, Sakuda M. Effects of directions of maxillary protraction forces on biomechanical changes in craniofacial complex. Eur J Orthod. 1989;11(4):382-391.

24- Pavoni C, Gazzani F, Franchi L, et al. Soft tissue facial profile in Class III malocclusion: long-term post-pubertal effects produced by the Face Mask Protocol. Eur J Orthod. 2019 21;41(5):531-536.

25- Ross RB. Treatment variables affecting facial growth in complete unilateral cleft lip and palate. Cleft Palate J. 1987;24(1):5-77.

26- Cassi D, Di Blasio A, Gandolfinini M, et al. Dentoalveolar Effects of Early Orthodontic Treatment in Patients With Cleft Lip and Palate. J Craniofac Surg. 2017;28(8):20212026.

27- Tindlund RS. Skeletal Response to Maxillary Protraction in Patients with Cleft Lip and Palate before Age 10 Years. Cleft Palate-Craniofacial J. 1994;31(4):295-308.

28- Ngan PW, Hagg U, Yiu C, et al. Treatment response and long-term dentofacial adaptations to maxillary expansion and protraction. Semin Orthod 1997;3:255-264.

29- da Silva Filho OG, Magro AC, Capelozza Filho L. Early treatment of the Class III malocclusion with rapid maxillary expansion and maxillary protraction. Am J Orthod Dentofacial Orthop 1998;113:196-203.

30- Ngan P, Yiu C, Hu A, et al. Cephalometric and occlusal changes following maxillary expansion and protraction. Eur J Orthod 1998;20:237-254.

31- Tinlund RS, Rygh P, Bøe OE. Orthopedic protraction of the upper jaw in cleft lip and palate patients during the deciduous and mixed dentition periods in comparison with normal growth and development. Cleft Palate Craniofac J 1993a;30:182-194.

32- Sade Hoefert C, Bacher M, Herberts T, et al. 3D soft tissue changes in facial morphology in patients with cleft lip and palate and class III mal occlusion under therapy with rapid maxillary expansion and delaire facemask. J Orofac Orthop. 2010;71(2):136-151.

33- Ngan P, Hägg U, Yiu C, et al. Soft tissue and dentoskeletal profile changes associated with maxillary expansion and protraction headgear treatment. Am J Orthod Dentofacial Orthop. 1996;109(1):38-49.

34- Dogan S. The effects of face mask therapy in cleft lip and palate patients. Ann Maxillofac Surg. 2012;2(2):116-120.

35- Baccetti T, Franchi L, McNamara JA Jr. Treatment and posttreatment craniofacial changes after rapid maxillary expansion and facemask therapy. Am J Orthod Dentofacial Orthop. 2000;118(4):404-413.

36- Brattström V1, McWilliam J, Semb G, et al. Craniofacial development in children with unilateral clefts of the lip, alveolus, and palate treated according to four different regimes. II. Mandibular and vertical development. Scand J Plast Reconstr Surg Hand Surg. 1992;26(1):55-63.

37- Kiliçoglu H1, Kirliç Y. Profile changes in patients with class III malocclusions after Delaire mask therapy. Am J Orthod Dentofacial Orthop. 1998;113(4):453-462. 